\title{
Blood lactate predicts survival after percutaneous implantation of extracorporeal life support for refractory cardiac arrest or cardiogenic shock complicating acute coronary syndrome: insights from the CareGem registry
}

\author{
Italo Porto ${ }^{1,2} \cdot$ Alessio Mattesini $^{3} \cdot$ Domenico D'Amario $^{4} \cdot$ Carlotta Sorini Dini ${ }^{7} \cdot$ Roberta Della Bona ${ }^{1}$. \\ Marco Scicchitano ${ }^{5} \cdot$ Rocco Vergallo $^{4} \cdot$ Antonio Martellini $^{3}{ }^{10} \cdot$ Simona Caporusso $^{6} \cdot$ Carlo Trani $^{4}$. \\ Francesco Burzotta ${ }^{4}$. Piergiorgio Bruno ${ }^{4}$ Carlo Di Mario ${ }^{3} \cdot$ Filippo Crea $^{4}$. Serafina Valente ${ }^{8}$. Massimo Massetti ${ }^{4}$
}

Received: 6 January 2020 / Accepted: 22 July 2020 / Published online: 9 August 2020

(c) The Author(s) 2020

\begin{abstract}
Refractory cardiogenic shock (RCS) or refractory cardiac arrest (RCA) complicating acute coronary syndrome (ACS) is associated with extremely high mortality rate. Veno-arterial extracorporeal life support (VA-ECLS) represents a valuable therapeutic option to stabilize patients' condition before or at the time of emergency revascularization. We analyzed 29 consecutive patients with RCS or RCA complicating ACS, and implanted with VA-ECLS in two centers who have adopted a similar, structured approach to ECLS implantation. Data were collected from January 2010 to December 2015 and ECLS had to be percutaneously implanted either before (within $48 \mathrm{~h}$ ) or at the time of attempted percutaneous coronary revascularization (PCI). We investigated in-hospital outcome and factors associated with survival. Twenty-one (72\%) were implanted for RCA, whereas 8 (28\%) were implanted on ECLS for RCS. All RCA were witnessed and no-flow time was shorter than 5 min in all cases but one. All patients underwent attempted emergency PCI, using radial access in ten cases (34.5\%), whereas in three patients a subsequent CABG was performed. Overall, ten patients (34.5\%) survived, nine of them with a good neurological outcome. Life threatening complications, including stroke (4 pts), leg ischemia (4 pts), intestinal ischemia (5 pts), and deep vein thrombosis 2 pts), occurred frequently, but were not associated with in-hospital death. Main cause of death was multiorgan failure. PCI variables did not predict survival. Survivors were younger, with shorter low-flow time, and with ECLS mainly implanted for RCS. At multivariate analysis, levels of lactate at ECLS implantation (OR 4.32, 95\%CI 1.01-18.51, $p=0.049$ ) emerged as the only variable that independently predicted survival. In patients with RCA or RCS complicating ACS who are percutaneously implanted with ECLS before or at the time of coronary revascularization, in hospital survival rate is higher than $30 \%$. Level of lactate at ECLS implantation appears to be the most important factor to predict survival.
\end{abstract}

Keywords Extracorporeal life support · Cardiogenic shock · Cardiac arrest · Acute coronary syndrome

\section{Introduction}

During last decades, the mortality rate of patients diagnosed with acute coronary syndrome (ACS) has been substantially reduced worldwide, due the combination of powerful

Serafina Valente and Massimo Massetti are to be considered joint senior authors for this submission.

Massimo Massetti

massimo.massetti@unicatt.it

Extended author information available on the last page of the article pharmacological treatment with early revascularization, mainly employing percutaneous coronary intervention (PCI) $[1,2]$. When ACS is complicated by refractory cardiogenic shock (RCS) or refractory cardiac arrest (RCA), however, the in-hospital mortality rate remains extremely high [3, 4]. In these critical conditions, mechanical circulatory support using veno-arterial extra-corporeal life support (VAECLS), able to provide haemodynamic stability during RCS or even total circulatory support during RCA, is considered appropriate in the most recent international guidelines, as ACS is classified as a potentially treatable etiology [5, 6]. Implantation of ECLS may be variously performed in the 
emergency department, in the intensive care unit, or in the catheterization laboratory, employing either a surgical or a percutaneous approach to cannulation, according to clinical presentation, available resources and local guidelines [7, 8]. Recently, for ACS patients, an emphasis shift has occurred, with several groups reporting relatively good outcomes for a team-based approach centered around the percutaneous suite, to provide rapid revascularization after the start of ECLS support $[9,10]$.

We report here the in-hospital outcome and factors associated with survival from two tertiary Italian centers who have adopted a similar, structured approach to ECLS implantation for ACS patients complicated by RCS or RCA, favoring percutaneous cannulation and aggressive revascularization by early PCI.

\section{Methods}

\section{Patients}

Data of patients undergoing ECLS due to RCS or RCA at two Italian tertiary care centers who have adopted a similar, structured, team-based approach to in-hospital ECLS implantation (the "Codice Viola" for the Gemelli Foundation Hospital, Rome, and the "ECMO Careggi Protocol" for the Azienda Ospedaliero-Universitaria Careggi, Florence) from January 2010 to December 2015.were prospectively entered into electronic hospital registries. Additional data required for this analysis were retrospectively evaluated. Patients who had undergone post-pericardiotomy ECLS implantation, who had ECLS implanted for non-cardiac causes, or for cardiac but non-ischemic etiology, or who had surgical cannulation, were excluded. We also chose not to include those patients who received an initial diagnosis of ACS, but in whom no coronary angiogram aimed at revascularisation was at least attempted, as we felt that those constituted a prohibitive risk subgroup.

\section{Definitions and protocols}

Refractory cardiogenic shock (RCS) was defined as critical circulatory failure resulting in organ hypoperfusion unresponsive to conventional therapy with minimal chance of survival without ECLS. The likelihood of death in the absence of ECLS was deemed to be extremely high. RCA was defined by the lack of return to spontaneous circulation (ROSC) after 10 min of standard advanced cardiopulmonary resuscitation (CPR). No-flow time was defined by the duration of cardiac arrest before the start of effective CPR, low-flow time by the duration of cardiac arrest with low cardiac output during CPR and before ECLS implantation. In RCS, both protocols advised to consider only patients who had an increasing demand of inotrope and vasopressor doses and rising levels of serum lactate. For RCA, both hospital protocols advised to consider ECLS implantation only in witnessed CA with no flow time $<5 \mathrm{~min}$, age $\leq 70$ or $\leq 65$ years, low flow time $>10$ and $<60 \mathrm{~min}$, and with end-tidal $\mathrm{CO} 2 \geq 10 \mathrm{mmHg}$, with one of the protocols also recommending as additional criteria $<3$ adrenaline vials, arterial $\mathrm{pH}>7.0$ and arterial lactate $<20 \mathrm{mmol} / \mathrm{L}$.

Contraindications to ECLS implantation were similar in both protocols and included: uncontrollable hemorrhage, irreversible neurological damage, severe trauma or known terminal malignancies, severe immunodepression or recent (within 30 days) organ transplantation, BMI $>40$ or body weight $>140 \mathrm{~kg}$, aortic dissection.

The decision regarding ECLS implantation was taken by the ECLS team that comprised an intensive care specialist, an interventional/intensive care cardiologist, a cardiac surgeon, and a perfusionist. Detailed sets of clinical and functional parameters including the SAVE score [11] were repeatedly assessed. Further, all patients underwent continuous control of routine laboratory parameters, including serum lactate. Left ventricular ejection fraction was assessed by transthoracic echocardiography.

\section{ECLS implantation}

In the selected cases, ECLS was implanted percutaneously. Cannulation occurred in the emergency department, in the intensive care unit or in the catheterization laboratory. The Seldinger technique was employed and cannula sizes were selected according to the patient's body weight, with arterial cannula 17-21 F and venous cannula 21-24 F. The equipment used heparinized polyvinyl chloride tubing, a membrane oxygenator (Quadrox Bioline; Jostra-Maquet, Orleans, France) and femoral cannulae (Biomedicus Carmed; Medtronic, Boulogne-Billancourt, France or) inserted percutaneously. A distal limb perfusion catheter $(6-8 \mathrm{~F})$ was consistently inserted in the superficial femoral artery to prevent lower limb ischaemia. Unfractionated heparin (70 U/ $\mathrm{kg}$ body weight) was administered and the pump blood flow was initially set at 3-4 L/min. All patients were supported with mechanical ventilation.

\section{Outcome definition}

The primary outcomes were in-hospital survival rate and good neurological outcome at discharge, which was assessed according to the cerebral performance category (CPC) scale 1-2 [12]. APACHE II score and SAVE-score were used for risk assessment [11, 13]. BCIS-JS [14] and Syntax [15]score were used to assess angiographic grading of complexity of coronary artery disease. 


\section{Statistical analysis}

Variables are expressed as a number and a percentage of patients. Continuous data are reported as median with corresponding interquartile deviation (IQR). The patients were divided into two groups: 'survivors' (survivors at the time of discharge) and 'non-survivors' (patients with in-hospital death). Univariate and multivariate logistic regression analyses were performed to identify predictors of in-hospital mortality. All variables with a $p$ value $<0.1$ in the univariate analysis were inserted into a forward stepwise multivariate model. Each statistical test was performed with SPSS (SPSS, IBM, Armonk, NY, USA software).

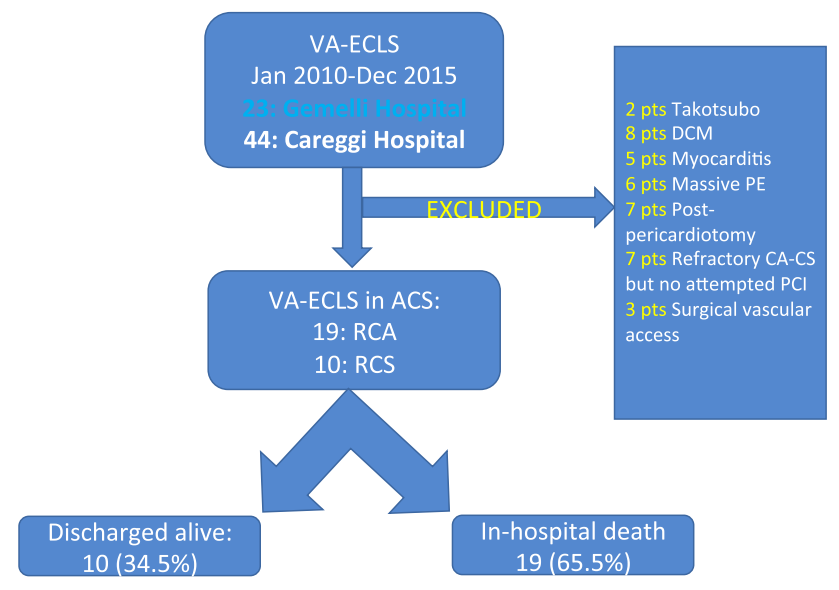

\section{Results}

From January 2010 to December 2015, 29 patients underwent ECLS implantation due to refractory cardiac arrest and cardiogenic shock complicating ACS. Details of the patients' flow are represented in Fig. 1. Clinical characteristics are summarized in Table 1 and angiographic/procedural variables are reported in Table 2. All patients underwent attempted emergency PCI, using radial access in 10 (34.5\%) cases, whereas in three patients CABG was subsequently performed. In 5 (17.2\%) cases the PCI failed, as patency of the culprit vessels could not be obtained.

All patients underwent ECLS implantation within $24 \mathrm{~h}$ from developing hemodynamic instability. Twenty-one (72\%) were implanted for RCA, whereas 8 (28\%) were implanted on ECLS for RCS. All RCA were witnessed, and no-flow time was shorter than $5 \mathrm{~min}$ in all cases but one. ECLS implantation was performed in the catheterization laboratory for 23 (79\%) patients (of these, three in spoke hospitals), three patients underwent ECLS implantation in the intensive care unit, three in the emergency room. In 18 (62\%) patients the hemodiafiltration (CVVHDF) was associated to the VA-ECLS, three of them already suffering from chronic renal failure. Among the complications, the most frequent were those related to bleeding at the access site of the VA-ECLS (Table 3). Twenty-one (72\%) patients required transfusion of more than 1 unit of red blood cells, and in $13(45 \%)$ of them it was necessary to use more than eight red blood cells units. No cases of heparin-induced thrombocytopenia were observed. Severe infections, occurred in $15(52 \%)$ patients, deep vein thrombosis in two, lower limb ischemia in four, intestinal ischemia was detected in five patients by autopsy, and cerebral ischemia occurred in four patients.

Fig. 1 patients' flow

Table 1 Clinical characteristics

\begin{tabular}{llll}
\hline & $\begin{array}{l}\text { Survivors } \\
10(34.5 \%)\end{array}$ & $\begin{array}{l}\text { Non-survivors } \\
19(65.5 \%)\end{array}$ & $p$ value \\
\hline Age (years), mean (SD) & $53.6 \pm 5.7$ & $60.9 \pm 9.2$ & 0.03 \\
Male gender, $n(\%)$ & $8(80)$ & $17(90)$ & 0.59 \\
Body mass index (BMI), mean, $\mathrm{kg} / \mathrm{m}^{2}$ & $27.7 \pm 3.5$ & $26.6 \pm 1.9$ & 0.4 \\
Diabetes mellitus, $n(\%)$ & $8(80)$ & $14(73.7)$ & 0.7 \\
Hypertension, $n(\%)$ & $5(50)$ & $9(47.4)$ & 0.9 \\
Hyperlipidaemia, $n(\%)$ & $4(40)$ & $4(21)$ & 0.3 \\
Smoking,n $(\%)$ & $6(60)$ & $8(42.1)$ & 0.3 \\
COPD, $n(\%)$ & $1(10)$ & $2(10.5)$ & 0.9 \\
Chronic renal failure, $n(\%)$ & $1(10)$ & $3(15.8)$ & 0.6 \\
Previous CAD, $n(\%)$ & $3(30)$ & $2(10.5)$ & 0.2 \\
Previous PCI, $n(\%)$ & $3(30)$ & $2(10.5)$ & 0.2 \\
Chronic heart failure, $n(\%)$ & $2(20)$ & $2(10.5)$ & 0.5 \\
Peripheral artery disease, $n(\%)$ & $1(20)$ & $4(21)$ & 0.4 \\
\hline
\end{tabular}


Table 2 Angiographic/ procedural characteristics

\begin{tabular}{|c|c|c|c|}
\hline & $\begin{array}{l}\text { Survivors } \\
10(34.5 \%)\end{array}$ & $\begin{array}{l}\text { Non-survivors } \\
19(65.5 \%)\end{array}$ & $p$ value \\
\hline Coronary artery disease & & & 0.74 \\
\hline 1 -vessel stenosis, $n(\%)$ & $1(10)$ & $4(21.0)$ & \\
\hline 2-vessel stenosis, $n(\%)$ & $4(40)$ & $6(31.6)$ & \\
\hline 3-vessel stenosis, $n(\%)$ & $5(50)$ & $9(47.4)$ & \\
\hline Thromboaspiration, $n(\%)$ & $4(40)$ & $10(52.6)$ & 0.5 \\
\hline PCI: Left main, $n(\%)$ & $4(40)$ & $7(36.8)$ & 0.8 \\
\hline PCI: Left Anterior Descending, $n(\%)$ & $9(90)$ & $11(57.8)$ & 0.07 \\
\hline PCI: Circumflex, $n(\%)$ & $7(70)$ & $8(42.1)$ & 0.1 \\
\hline PCI: Right coronary, $n(\%)$ & $1(10)$ & $8(42.1)$ & 0.07 \\
\hline $\begin{array}{l}\text { Number of implanted Drug Eluting Stent, } \\
\text { median (IQR) }\end{array}$ & $2(1-4)$ & $1(0.5-2)$ & 0.08 \\
\hline Bifurcation PCI, $n(\%)$ & $5(50)$ & $7(36,8)$ & 0.5 \\
\hline PCI Failure, $n(\%)$ & $1(10)$ & $4(21)$ & 0.4 \\
\hline Complete revascularization, $n(\%)$ & $1(10)$ & $6(31.5)$ & 0.2 \\
\hline CABG, $n(\%)$ & $2(20)$ & $2(10.5)$ & 0.5 \\
\hline Autopulse, $n(\%)$ & $0(0)$ & $4(21)$ & 0.1 \\
\hline Radial access, $n(\%)$ & $5(50)$ & $5(26.3)$ & 0.2 \\
\hline Anti IIb/IIIa, $n(\%)$ & $7(70)$ & $4(21)$ & $<0.01$ \\
\hline Antegrade limb perfusion, $n(\%)$ & $9(90)$ & $18(94)$ & 0.6 \\
\hline BCIS-JS pre & $11.6 \pm 2.3$ & $11.9 \pm 5.3$ & 0.6 \\
\hline Syntax score pre & $30.5 \pm 9.3$ & $26.4 \pm 12.4$ & 0.4 \\
\hline BCIS-JS post & $4 \pm 3.1$ & $3.8 \pm 3.8$ & 0.9 \\
\hline Syntax score post & $8.9 \pm 9.5$ & $11 \pm 14.3$ & 0.7 \\
\hline Euroscore & $17.1 \pm 9.2$ & $19.1 \pm 9.7$ & 0.6 \\
\hline
\end{tabular}

Weaning from VA-ECLS was obtained in 11 (38\%) patients. Only one patient weaned from VA-ECLS did not survive the explant and died due to cerebral ischemia after weaning. Finally, 10 (34\%) patients were discharged alive.

Overall, survivors were younger, with shorter lowflow time, and with ECLS mainly implanted for RCS, as opposed to RCA. Main cause of death was multi-organ failure (MOF), occurring in 9/19 (48\%) 'non-survivor' patients; cardiogenic shock was the cause of death in 5 (26\%) cases. The remaining $5(26 \%)$ patients died due different causes: intractable ventricular fibrillation, ECLS access complications, pneumonia and hemoperitoneum, hemorrhagic shock, brain death and cerebral ischemia.

At univariate regression analysis, age and blood lactates at the time of ECLS implantation, emerged as predictors of mortality. PCI variables and the VIS score (evaluating the strength of administered inotropics agents) did not predict survival. At multivariate analysis levels of lactate at ECLS implantation (OR 4.32, 95\% CI $1.01-18.51, p=0.049)$ emerged as the only significant variable to predict survival.

\section{Discussion}

The main findings of the present study are:

1) In-hospital survival rate of more than $30 \%$ is observed for patients with CS or CA complicating ACS in tertiary Italian hospitals that have adopted a similar, structured approach to ECLS implantation, and in patients in whom PCI was at least attempted.

2) Serum lactate measured at the time of VA-ECLS implantation, an index of profound haemodynamic derangement, is an independent risk factor of mortality in those patients, whereas procedural and angiographic variables, as well as complications occurring during hospital stay, do not seem to predict survival in our cohort.

Regarding the first point, the $34 \%$ survival to discharge observed in our cohort is in line with data from the ELSO cohort, the largest database available, which showed a survival to discharge of $38 \%$ in adult patients receiving ECLS for CS or refractory CA of different etiologies [16]. 
Table 3 Results summary

\begin{tabular}{|c|c|c|c|}
\hline & $\begin{array}{l}\text { Survivors } \\
10(34.5 \%)\end{array}$ & $\begin{array}{l}\text { Non-survivors } \\
19(65.5 \%)\end{array}$ & $p$ value \\
\hline Indication for ECMO implantation & & & $<0.01$ \\
\hline Refractory cardiac arrest, $n(\%)$ & $4(40)$ & $17(89.5)$ & \\
\hline Refractory cardiogenic shock, $n(\%)$ & $6(60)$ & $2(10.5)$ & \\
\hline Diagnosis & & & 0.01 \\
\hline STEMI with RCA, $n(\%)$ & $1(10)$ & $14(73.7)$ & \\
\hline ACS with RCA, $n(\%)$ & $2(20)$ & $2(10.5)$ & \\
\hline STEMI with RCS, $n(\%)$ & $4(40)$ & $2(10.5)$ & \\
\hline ACS with RCS, $n(\%)$ & $3(30)$ & $1(5.3)$ & \\
\hline Low-flow time (min), median (IQR) & $\begin{array}{l}45(28-65) \\
(n=4)\end{array}$ & $\begin{array}{l}60(50-70) \\
(n=17)\end{array}$ & 0.28 \\
\hline Low flow time $<30 \min , n(\%)$ & $2 / 4(50)$ & $16 / 17(94.1)$ & 0.02 \\
\hline SAVE score, mean & $-5.3(4.1)$ & $-8.2(3.7)$ & 0.08 \\
\hline IABP, $n(\%)$ & $10(100)$ & $15(78.9)$ & 0.1 \\
\hline CVVH-DF, $n(\%)$ & $5(50)$ & $13(68.4)$ & 0.2 \\
\hline Hypotermia, $n(\%)$ & $4(40)$ & $13(68.4)$ & 0.1 \\
\hline \multicolumn{4}{|l|}{ Inotropic agent } \\
\hline Norephinephrine, $n(\%)$ & $9(90)$ & $19(100)$ & 0.2 \\
\hline Ephinephrine, $n(\%)$ & $2(20)$ & $6(31.5)$ & 0.5 \\
\hline Dopamine, $n(\%)$ & $8(80)$ & $13(64)$ & 0.7 \\
\hline Dobutamine, $n(\%)$ & $2(20)$ & $6(31.5)$ & 0.5 \\
\hline Levosimendan, $n(\%)$ & $8(42.1)$ & $6(60)$ & 0.2 \\
\hline \multicolumn{4}{|l|}{ VIS score } \\
\hline $0 \mathrm{~h}$, median $(\mathrm{IQR})$ & $36.2(39)$ & $42.5(44.5)$ & 0.9 \\
\hline $24 \mathrm{~h}$, median (IQR) & $25(20.7)$ & $40(33)$ & 0.1 \\
\hline $48 \mathrm{~h}$, median (IQR) & $21(22.4)$ & $24(33)$ & 0.5 \\
\hline ECLS weaning, $n(\%)$ & $10(100)$ & $1(5.2)$ & $<0.01$ \\
\hline ECLS duration (days), median (IQR) & $3.8(3.5)$ & $5(3)$ & 0.5 \\
\hline White blood cells $\left(/ \mathrm{mm}^{3}\right)$ & $27,375 \pm 4612$ & $16,120 \pm 7545$ & 0.6 \\
\hline $\mathrm{Hb}$ admission $(\mathrm{g} / \mathrm{dl})$ & 11.5 & 10.1 & 0.25 \\
\hline Hb nadir (g/dl) & 7.7 & 6.9 & 0.19 \\
\hline eGFR admission (ml/min) & 77.9 & 54.2 & 0.03 \\
\hline $\mathrm{pH}$ admission & 7.3 & 7.2 & 0.3 \\
\hline $\mathrm{pH} 24 \mathrm{~h}$ & 7.3 & 7.6 & 0.01 \\
\hline Lactate at admission $(\mathrm{mmol} / \mathrm{l})$ & 4.3 & 11.2 & $<0.01$ \\
\hline Lactate at ECLS (mmol/l) & $5.4(1.8-6.4)$ & $10.2(7.8-15)$ & $<0.01$ \\
\hline Lactate $24 \mathrm{~h}$ after ECLS (mmol/l) & 2.5 & 5.7 & $<0.01$ \\
\hline \multicolumn{4}{|l|}{ Complications } \\
\hline Stroke, $n(\%)$ & $2(20)$ & $2(10,5)$ & 0.5 \\
\hline Leg ischaemia, $n(\%)$ & $0(0)$ & $4(21)$ & 0.1 \\
\hline Intestinal ischaemia, $n(\%)$ & $2(20)$ & $3(15.7)$ & 0.7 \\
\hline Deep venous thrombosis, $n(\%)$ & $2(20)$ & $0(0)$ & \\
\hline Blood transfusion, $n(\%)$ & $9(90)$ & $16(84.2)$ & 0.8 \\
\hline Blood transfusion units & 16 & 11 & 0.2 \\
\hline
\end{tabular}

In the more selected case of CA or CS complicating ACS, the reported survival to hospital discharge varies from $33 \%$ in a Japanese cohort of 98 patients [17], to $39 \%$ of a French cohort of 77 patients with CS [18], to $67 \%$ of an American cohort of 18 patients with CS [10], with a recent systematic review and metanalysis including 739 patients from 17 studies reporting a short-term survival (defined as absence of death occurring during hospitalization or in the first month) of $42 \%$. Whereas several confounding factors (including small sample sizes 
and differences in inclusion criteria) may explain this variability in survival to discharge, our study can be more closely compared with two recent reports, not included in the previous metanalysis.

A 29-patient cohort from Switzerland has been recently described, reporting a mortality of $62.1 \%$ at 30 days. In these patients, blood lactate peak in the first $24 \mathrm{~h}$ was markedly increased in non-survivors, and the peak of blood lactate $>11 \mathrm{mmol} / \mathrm{l}$ independently predicted 30-day mortality [19]. Differently from our cohort, however, a full percutaneous technique for ECLS implantation was only utilized in $10(55.6 \%)$ patients of the non-survivors group and in $9(81.8 \% ; p=0.093)$ of the survivors.

Another, larger ( 83 patients) cohort was reported by De Waha, comprising patients undergoing fully percutaneous ECLS implantation performed by interventional cardiologists for refractory CS. Etiology was MI in 63.9\%, acute deterioration of ischaemic cardiomyopathy in $6.0 \%$, nonischaemic acute heart failure in $16.9 \%$, valvular heart disease in $9.6 \%$, and interventional complications in $3.6 \%$. Of note, and despite the exclusion of refractory CA and the variable etiology, in-hospital mortality was remarkably similar to our sample (68.7\%) [9].

It would appear, thus, that the short-term prognosis of patients with refractory CS or refractory CA remains relatively poor (but not dismal) in different countries and variable settings, highlighting the need for better patient selection and uniformization of ECLS inclusion and management protocols.

Regarding the value of biomarkers to gauge the prognosis of such patients, it should be noted that the main mechanism of hyperlactatemia is related to the development of anaerobic metabolism [3, 20, 21]. The assessment of lactates in patients with shock has been performed for $>30$ years [22]. Several studies investigating the association of serum lactate and in-hospital survival in CA treated conventionally (i.e. without circulatory assist device) established a predictive link between survival and initial lactate levels and reported serum lactate as an independent prognostic factor of mortality and neurological outcome [23, 24]. Moreover, recent retrospective studies [19, 24-27] (the largest including 117 refractory CA [26]) revealed serum lactate as a potent predictor of outcome for patients treated with ECLS. Additionally, even if changes in lactate take place more slowly than changes in systemic arterial pressure or cardiac output, lactate levels decrease over a period of hours with effective therapy [20]. In patients suffering from CS and CA, the rate of clearance of excess serum lactate is also associated with VA-ECLS efficacy on organ perfusion [28]. Lactate cut-off values (pre-ECLS blood lactate greater $10 \mathrm{mmol} / \mathrm{l}$, higher than $12 \mathrm{mmol} / \mathrm{l} 3 \mathrm{~h}$ after ECLS implantation, higher than $7.05 \mathrm{mmol} / \mathrm{l}$ at $6 \mathrm{~h}$ and $4.95 \mathrm{mmol} / \mathrm{l}$ at $12 \mathrm{~h}$ ) have been suggested to predict the occurrence of multiorgan failure or inadequate tissue perfusion in this context [17, 19,20].

\section{Conclusion}

Additional criteria to guide ECLS initiation are urgently needed for better patient management: implementation of a simple, easily measured index such as serum lactate may potentially add to our armamentarium of tools for predicting futility in this extreme context.

Acknowledgements Open access funding provided by Università Cattolica del Sacro Cuore within the CRUI-CARE Agreement.

\section{Compliance with ethical standards}

Conflict of interest The author declares that they have no conflict of interest.

Human and animal rights statement We certificate that this study havs been performed in accordance with the ethical standards laid down in the 1964 Declaration of Helsinki and its later amendments.

Informed consent All subjects provided written informed consent.

Open Access This article is licensed under a Creative Commons Attribution 4.0 International License, which permits use, sharing, adaptation, distribution and reproduction in any medium or format, as long as you give appropriate credit to the original author(s) and the source, provide a link to the Creative Commons licence, and indicate if changes were made. The images or other third party material in this article are included in the article's Creative Commons licence, unless indicated otherwise in a credit line to the material. If material is not included in the article's Creative Commons licence and your intended use is not permitted by statutory regulation or exceeds the permitted use, you will need to obtain permission directly from the copyright holder. To view a copy of this licence, visit http://creativecommons.org/licenses/by/4.0/.

\section{References}

1. Widimsky P, Wijns W, Fajadet J, de Belder M, Knot J, Aaberge L, Andrikopoulos G, Baz JA, Betriu A, Claeys M, Danchin N, Djambazov S, Erne P, Hartikainen J, Huber K, Kala P, Klinceva M, Kristensen SD, Ludman P, Ferre JM, Merkely B, Milicic D, Morais J, Noc M, Opolski G, Ostojic M, Radovanovic D, De Servi S, Stenestrand U, Studencan M, Tubaro M, Vasiljevic Z, Weidinger F, Witkowski A, Zeymer U (2010) Reperfusion therapy for ST elevation acute myocardial infarction in Europe: description of the current situation in 30 countries. Eur Heart J 31:943-957

2. McManus DD, Gore J, Yarzebski J, Spencer F, Lessard D, Goldberg $\mathrm{RJ}$ (2011) Recent trends in the incidence, treatment, and outcomes of patients with STEMI and NSTEMI. Am J Med 124:40-47

3. Thiele H, Ohman EM, Desch S, Eitel I, de Waha S (2015) Management of cardiogenic shock. Eur Heart J 36:1223-1230 
4. Levy B, Bastien O, Karim B, Cariou A, Chouihed T, Combes A, Mebazaa A, Megarbane B, Plaisance P, Ouattara A, Spaulding C, Teboul JL, Vanhuyse F, Boulain T, Kuteifan K (2015) Experts' recommendations for the management of adult patients with cardiogenic shock. Ann Intensive Care 5:52

5. Atkinson TM, Ohman EM, O'Neill WW, Rab T, Cigarroa JE (2016) A Practical approach to mechanical circulatory support in patients undergoing percutaneous coronary intervention: an interventional perspective. JACC Cardiovasc Interv 9:871-883

6. Briceno N, Kapur NK, Perera D (2016) Percutaneous mechanical circulatory support: current concepts and future directions. Heart 102:1494-1507

7. Banfi C, Pozzi M, Brunner ME, Rigamonti F, Murith N, Mugnai D, Obadia JF, Bendjelid K, Giraud R (2016) Veno-arterial extracorporeal membrane oxygenation: an overview of different cannulation techniques. J Thorac Dis 8:E875-E885

8. Sangalli F, Patroniti N, Pesenti A (2014) ECMO-extracorporeal life support in adults. Springer, Milan

9. de Waha S, Fuernau G, Desch S, Eitel I, Wiedau A, Lurz P, Schuler G, Thiele H (2016) Long-term prognosis after extracorporeal life support in refractory cardiogenic shock: results from a real-world cohort. EuroIntervention 11:1363-1371

10. Esper SA, Bermudez C, Dueweke EJ, Kormos R, Subramaniam K, Mulukutla S, Sappington P, Waters J, Khandhar SJ (2015) Extracorporeal membrane oxygenation support in acute coronary syndromes complicated by cardiogenic shock. Catheter Cardiovasc Interv 86(Suppl 1):S45-50

11. Schmidt M, Burrell A, Roberts L, Bailey M, Sheldrake J, Rycus PT, Hodgson C, Scheinkestel C, Cooper DJ, Thiagarajan RR, Brodie D, Pellegrino V, Pilcher D (2015) Predicting survival after ECMO for refractory cardiogenic shock: the survival after venoarterial-ECMO (SAVE)-score. Eur Heart J 36:2246-2256

12. Truong HT, Low LS, Kern KB (2015) Current approaches to cardiopulmonary resuscitation. Curr Probl Cardiol 40:275-313

13. Knaus WA, Draper EA, Wagner DP, Zimmerman JE (1985) APACHE II: a severity of disease classification system. Crit Care Med 13:818-829

14. Morton GD, De Silva K, Ishida M, Chiribiri A, Indermuehle A, Schuster A, Redwood S, Nagel E, Perera D (2013) Validation of the BCIS-1 myocardial jeopardy score using cardiac magnetic resonance perfusion imaging. Clin Physiol Funct Imaging 33:101-108

15. Serruys PW, Morice MC, Kappetein AP, Colombo A, Holmes DR, Mack MJ, Stahle E, Feldman TE, van den Brand M, Bass EJ, Van Dyck N, Leadley K, Dawkins KD, Mohr FW (2009) Percutaneous coronary intervention versus coronary-artery bypass grafting for severe coronary artery disease. N Engl J Med 360:961-972

16. Gray BW, Haft JW, Hirsch JC, Annich GM, Hirschl RB, Bartlett RH (2015) Extracorporeal life support: experience with 2,000 patients. Asaio J 61:2-7

17. Sakamoto S, Taniguchi N, Nakajima S, Takahashi A (2012) Extracorporeal life support for cardiogenic shock or cardiac arrest due to acute coronary syndrome. Ann Thorac Surg 94:1-7
18. Demondion P, Fournel L, Golmard JL, Niculescu M, Pavie A, Leprince P (2014) Predictors of 30-day mortality and outcome in cases of myocardial infarction with cardiogenic shock treated by extracorporeal life support. Eur J Cardiothorac Surg 45:47-54

19. Rigamonti F, Montecucco F, Boroli F, Rey F, Gencer B, Cikirikcioglu M, Reverdin S, Carbone F, Noble S, Roffi M, Banfi C, Giraud R (2016) The peak of blood lactate during the first 24h predicts mortality in acute coronary syndrome patients under extracorporeal membrane oxygenation. Int J Cardiol 221:741-745

20. Vincent JL, De Backer D (2013) Circulatory shock. N Engl J Med 369:1726-1734

21. Moskovitz JB, Levy ZD, Slesinger TL (2015) Cardiogenic shock. Emerg Med Clin N Am 33:645-652

22. Vincent JL, Dufaye P, Berre J, Leeman M, Degaute JP, Kahn RJ (1983) Serial lactate determinations during circulatory shock. Crit Care Med 11:449-451

23. Cocchi MN, Miller J, Hunziker S, Carney E, Salciccioli J, Farris S, Joyce N, Zimetbaum P, Howell MD, Donnino MW (2011) The association of lactate and vasopressor need for mortality prediction in survivors of cardiac arrest. Minerva Anestesiol 77:1063-1071

24. Donnino MW, Andersen LW, Giberson T, Gaieski DF, Abella BS, Peberdy MA, Rittenberger JC, Callaway CW, Ornato J, Clore J, Grossestreuer A, Salciccioli J, Cocchi MN (2014) Initial lactate and lactate change in post-cardiac arrest: a multicenter validation study. Crit Care Med 42:1804-1811

25. Jouffroy R, Lamhaut L, Guyard A, Phillipe P, Deluze T, Jaffry M, Dagron C, Bourgoin W, Orsini JP, An K, Jouven X, Spaulding C, Carli P (2014) Base excess and lactate as prognostic indicators for patients treated by extra corporeal life support after out hospital cardiac arrest due to acute coronary syndrome. Resuscitation 85:1764-1768

26. Jung C, Janssen K, Kaluza M, Fuernau G, Poerner TC, Fritzenwanger M, Pfeifer R, Thiele H, Figulla HR (2016) Outcome predictors in cardiopulmonary resuscitation facilitated by extracorporeal membrane oxygenation. Clin Res Cardiol 105:196-205

27. Debaty G, Babaz V, Durand M, Gaide-Chevronnay L, Fournel E, Blancher M, Bouvaist H, Chavanon O, Maignan M, Bouzat P, Albaladejo P, Labarere J (2017) Prognostic factors for extracorporeal cardiopulmonary resuscitation recipients following out-ofhospital refractory cardiac arrest. A systematic review and metaanalysis. Resuscitation 112:1-10

28. Li CL, Wang H, Jia M, Ma N, Meng X, Hou XT (2015) The early dynamic behavior of lactate is linked to mortality in postcardiotomy patients with extracorporeal membrane oxygenation support: A retrospective observational study. J Thorac Cardiovasc Surg 149:1445-1450

Publisher's Note Springer Nature remains neutral with regard to jurisdictional claims in published maps and institutional affiliations. 


\section{Affiliations}

Italo Porto ${ }^{1,2} \cdot$ Alessio Mattesini $^{3} \cdot$ Domenico D'Amario $^{4} \cdot$ Carlotta Sorini Dini $^{7} \cdot$ Roberta Della Bona $^{1}$. Marco Scicchitano ${ }^{5}$. Rocco Vergallo ${ }^{4}$ - Antonio Martellini ${ }^{3}$ D . Simona Caporusso ${ }^{6}$. Carlo Trani $^{4}$.

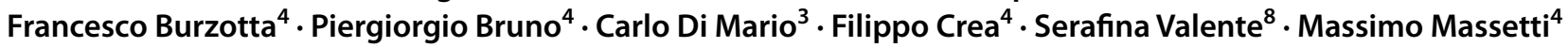

1 Dipartimento CardioToracoVascolare, IRCCS Ospedale Policlinico San Martino, Genova, Italy, Italian IRCCS Cardiovascular Network, Genoa, Italy

2 Dipartimento di Medicina Interna e Specialità Mediche (DiMI), Università di Genova, Genoa, Italy

3 Dipartimento del Cuore e dei Vasi, Azienda Ospedaliero-Universitaria Careggi, Florence, Italy

4 Dipartimento di Scienze Cardiovascolari e Toraciche, Fondazione Policlinico A. Gemelli IRCCS, Rome, Italy,
Italian IRCCS Cardiovascular Network and Università Cattolica del Sacro Cuore, Largo A. Gemelli, 00168 Rome, Italy

5 Ospedale Sandro Pertini, Roma, Italy

6 IRCCS Ospedale Pediatrico Bambino Gesù, Roma, Italy

7 Spedali Riuniti, Leghorn, Italy

8 U.O.C. Cardiologia Ospedaliera, A.O.U. Senese Ospedale Santa Maria Alle Scotte, Siena, Italy 